\title{
Feed-in Tariffs:
}

Good Practices

and Design Considerations

A CLEAN ENERGY REGULATORS INITIATIVE REPORT
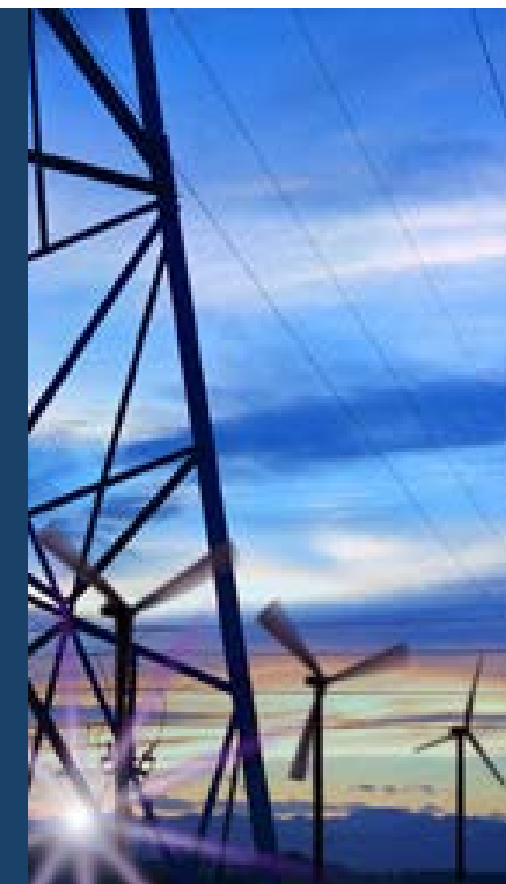

Sadie Cox and Sean Esterly National Renewable Energy Laboratory

Technical Report NREL/TP-6A20-65503

January 2016 


\section{Feed-in Tariffs: Good Practices and Design Considerations}

Sadie Cox and Sean Esterly

National Renewable Energy Laboratory

Technical Report NREL/TP-6A20-65503

January 2016 


\section{NOTICE}

This manuscript has been authored by employees of the Alliance for Sustainable Energy, LLC ("Alliance") under Contract No. DE-AC36-08GO28308 with the U.S. Department of Energy ("DOE").

This report was prepared as an account of work sponsored by an agency of the United States government. Neither the United States government nor any agency thereof, nor any of their employees, makes any warranty, express or implied, or assumes any legal liability or responsibility for the accuracy, completeness, or usefulness of any information, apparatus, product, or process disclosed, or represents that its use would not infringe privately owned rights. Reference herein to any specific commercial product, process, or service by trade name, trademark, manufacturer, or otherwise does not necessarily constitute or imply its endorsement, recommendation, or favoring by the United States government or any agency thereof. The views and opinions of authors expressed herein do not necessarily state or reflect those of the United States government or any agency thereof. 


\section{Acknowledgments}

The authors would like to thank Ron Benioff, Jenny Heeter, Victoria Healey, Jaquelin Cochran, Jeffrey Logan, David Mooney, and Terri Walters of the National Renewable Energy Laboratory, and Ian Lloyd of the U.S. Department of Energy for their review and insights. All information and any omissions are the responsibility of the authors, not the reviewers. 


\section{Table of Contents}

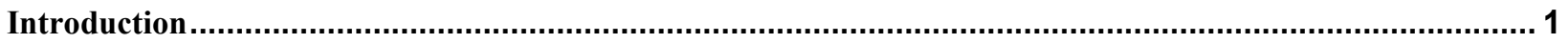

Policy Design and Good Practices....................................................................................................... 2

Setting and Revising FIT Payment Levels ....................................................................... 2

Considering a Cost Containment Approach .......................................................................... 4

Establishing Long-Term Contracts and Guaranteeing Grid Access.......................................... 4

Considering Forecasting Requirements............................................................................

Streamlining Administration and Approvals ........................................................................

Considering Linkages with Other Policies ......................................................................... 5

Considering FITs in the Context of High Renewable Energy Penetration Levels .............................. 5

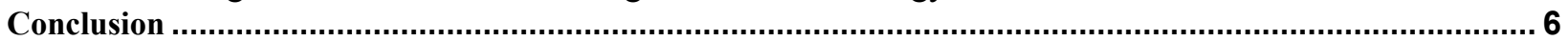

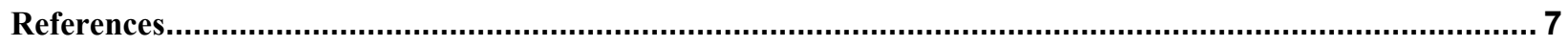

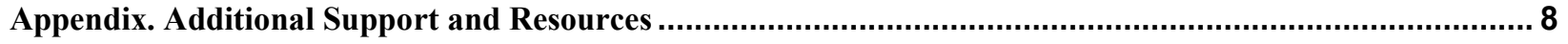

\section{List of Text Boxes}

Text Box 1. Ghana: Sending Consistent FIT Policy Signals...................................................... 2

Text Box 2. FIT Payment Level Approaches ............................................................... 3

Text Box 3. South Africa: Designing Data-supported, Two-stage Tender Processes to Ensure Project Viability and Successful Policy Outcomes

Text Box 4. Indonesia: Designing FITs to Align with Specific Subnational Circumstances and

Development Goals. 


\section{Introduction}

Feed-in tariffs (FITs), along with renewable electricity standards, are one of the most widely adopted renewable energy support policies around the world. As of 2013, 98 national and subnational governments had implemented FITs, nearly three times the number that had adopted them in 2004 (REN21 2015). In recent years, FIT activity has focused primarily on revisions to current policies, underscoring the need for stable and predictable, yet flexible, policy environments. This policy brief provides a primer on key FIT design elements, lessons from country experience, and support resources to enable more detailed and country-specific FIT policy design.

FITs are designed to increase deployment of renewable energy technologies by offering long-term purchase agreements for electricity generation at a specified price per kilowatt-hour, thereby providing market certainty for developers (Couture et al. 2010). Traditionally, FITs have been set as a fixed tariff. However, policymakers have recently been moving towards designing FITs as a premium in addition to the current market rate for electricity, known as feed-in premiums (Rickerson et al. 2007; REN21 2015). Ultimately, effectively designed FITs can attract private investment to support renewable energy expansion and local economic development (NREL 2014).

Key FIT policy design elements and good practices that have been drawn from global experience and lessons and which can be tailored to meet country-specific goals are described in the following sections. 


\section{Policy Design and Good Practices}

\section{Setting and Revising FIT Payment Levels}

To align with specific policy goals, policymakers should vary FIT payments by technology, project size, location and resource quality. Specific approaches are noted in the text box on this page. In each case, project developers need to be assured a revenue stream at a predictable payment and terms to ensure a reasonable profit for the project.

To support scaled-up deployment and innovation, FIT payments for new projects should also be adjusted incrementally as technology costs

Text Box 1. Ghana: Sending Consistent FIT Policy Signals

The Clean Energy Solutions Center, via its Ask an Expert service, partnered with the Ghana Energy Commission on the design and development of a FIT by sharing FIT design resources and best practices. To ensure consistent policy signals, Ghana's FIT established a fixed, 10-year tariff rate from the time of power purchase agreement that varies by technology and is subject to review every two years. The collaborative effort facilitated both effectiveness and speed of policy development and eventual policy implementation that will encourage scaled-up deployment of renewable energy in Ghana. change (NREL 2014). However, payment changes should be made transparently and predictably, as erratic adjustments may increase project developer uncertainty and reduce investment (In 2013, most adjustments to FITs were a reduction in the tariff to adjust for changes in the market, according to REN21 2015). Policymakers may choose to address this challenge by setting a pre-established percentage for annual declines in the FIT payment, as well as less frequent broader policy revisions (e.g., every 3-5 years). Payment adjustments can be informed by collecting detailed data related to technology market evolution and prices. Supporting a stable and predictable policy environment that is also flexible and iterative is critical for positive outcomes (NREL 2014).

Setting the payment level is the most complex element of the FIT design process and requires robust analysis to balance cost recovery with avoiding excessive developer profits (see Text Box 2) (NREL 2014). Payments can be either dependent on or separate from the market price for electricity. A premium-price FIT combines the electricity market price and a premium (either stable for the life of the contract or designed to fluctuate), thus adding a degree of uncertainty for the developer due to varying market prices. A fixed-price FIT provides the same payment for the duration of the contract, which, although it is simpler, can result in excessive developer profits if electricity prices increase substantially (NREL 2014). Ultimately, policy costs can be integrated with the electricity rate base (NREL 2014). 


\section{Text Box 2. FIT Payment Level Approaches}

Policymakers typically design FIT payment levels using the following approaches:

- Levelized cost of renewable electricity generation provides a per kilowatt-hour (kWh) cost of renewable energy generation for the full duration of the project including construction and operation. Key inputs include capital, fuel, operation and maintenance and finance costs as well as projected plant utilization. This approach can be tailored by technology and project size, and it is often most effective at driving renewable energy deployment, as it clearly defines the return to investors.

- Value of renewable electricity is calculated based on the utility's avoided cost of generation added to the ancillary grid benefits, such as peak power and stability, and the value of societal benefits, such as climate change mitigation and reduction in negative health impacts associated with lower emissions. This value can be difficult to accurately assess, but it can be estimated to determine the FIT payment level.

- Resource quality can be used to differentiate FIT payment levels, allowing the payment to be appropriately aligned with generation costs at specific sites. Designing tariffs in relation to resource quality can improve project siting flexibility and support reductions in grid balancing costs through geographically dispersing renewable energy development, thus improving overall reliability. For wind power, the "reference turbine approach" bases payments on comparison of a reference yield with turbine generation over a five-year period. Various other approaches, such as "annual percentage yield" have also been used by countries to set FIT payments in relation to resource quality.

- Auction-based procurement through tender mechanisms can be used as a hybrid approach to determine FIT payment levels. Under this approach, governments tender or request bids for projects from which a utility or distribution company will purchase electricity. Tenders are usually designed with a total capacity of projects that will be funded, with the government or utility choosing multiple winning bids until the total capacity equals the tender capacity goals. When compared with traditional FIT payment schemes, this competitive bidding often results in lower project costs (Philibert 2011). However, this process can encourage inexperienced developers to submit bids that are too low, resulting in a project that is ultimately unsuccessful. Policymakers can mitigate this problem through designing a two-phase tender process that requires bidders to demonstrate experience and technical capability before they submit a complete bid. As described below, some countries are combining FIT and auction-based approaches to support RE deployment.

Sources: Couture et al. 2010; EIA 2015 


\section{Considering a Cost Containment Approach}

If a FIT is set at a very favorable rate for project developers, it may encourage rapid deployment but also result in high costs and "boom and bust" scenarios. Policymakers may choose to place caps on project participation to address this issue. However, it is important to recognize that cost containment options could introduce additional market uncertainty and inhibit investments. Cost containment options include:

- Establishing a maximum installed capacity that will be supported (e.g., 200 megawatts per year)

- Reducing the FIT payments on a set schedule when capacity goals are met (e.g., one payment for the first 200 megawatts installed and another payment for the next 200 megawatts installed)

- Ending the FIT when the available program funds have been exhausted.

\section{Establishing Long-Term Contracts and Guaranteeing Grid Access}

In addition to setting the payment level, it is important to define the length of contracts. Under existing FITs, contract lengths typically range from 10 to 25 years, with longer contracts often resulting in lower cost of financing. Many FITs are also coupled with guaranteed access to the grid. Guaranteed access can help to ensure electricity generated under the FIT is not stranded and is a protection for invested public funds (Couture et al. 2010).

\section{Considering Forecasting Requirements}

Under a FIT policy — and to support grid operators in balancing renewable energy generation with system demand-project developers can be required to provide project forecasts. This can be burdensome, especially for smaller plants, but it can be useful particularly for larger renewable energy projects (Couture et al. 2010).

\section{Streamlining}

\section{Administration and} Approvals
Text Box 3. South Africa: Designing Datasupported, Two-stage Tender Processes to Ensure Project Viability and Successful Policy Outcomes

Based on robust analysis of various policy options, the Government of South Africa chose to establish a competitive tender process-rather than a FIT—to support solar deployment (Eberhard et al. 2014). Under this process, bidders are first required to demonstrate their expertise, with the government then choosing preferred bidders to submit full proposals. An installed capacity cap was established for each round, providing transparency and market certainty to developers and ensuring the government's capacity goals are met but not exceeded. Since policy inception, there have been three bidding processes with costs declining with each subsequent round. In this case, the experience gained from projects undertaken in previous rounds led to reduction of barriers to deployment and associated costs. To support a successful bidding process the government also provided reliable solar irradiation data to inform bids from project developers (Stadelmann et al. 2014). South Africa's two-stage tender process incorporated a number of effective design elements to ensure project viability and successful outcomes.

To avoid bottlenecks and reduce the time and costs associated with approvals and administration, policymakers can establish a streamlined FIT processing approach that clearly identifies participating 
entities (e.g., individuals, corporations, nonprofits and government) and mandates specific roles and procedures (Couture et al. 2010).

\section{Considering Linkages with Other Policies}

In some markets, policymakers are considering links between FITs and other support policies, such as tender and auction processes and net metering. For example, FITs and auctions can be coupled in relation to project size, with FITs supporting smaller projects and auctions supporting larger projects. As RE markets evolve differently in various country contexts, policymakers can consider links between FITs and other policies that may enhance deployment opportunities (Couture et al. 2015). Further information on emerging hybrid designs can be accessed in Couture et al. (2015)

\section{Considering FITs in the Context of High Renewable Energy Penetration Levels}

As a number of countries and jurisdictions reach high levels of renewable energy penetration, they are adapting FITs to address new needs and opportunities (High renewable energy penetration can be defined as at least $15 \%$ of annual electricity generation from renewable energy, according to Miller et al. [2013]). For instance, FITs can be used to enhance grid support services through incorporating frequency and voltage support incentives. To contain costs, FITs can also be designed to allow transmission system operators to curtail wind while still compensating for the renewable energy generated. Finally, integrating FIT-supported RE generation into centralized markets can also allow for greater efficiency of the dispatch system. Under this approach, renewable

Text Box 4. Indonesia: Designing FITs to Align with Specific Subnational Circumstances and Development Goals

The cost to generate and provide electricity in Indonesia varies greatly by location due to the remote locations of populations across the country's many islands. Additionally, there are regions in the country where electrification rates are as low as 30 percent, such as in Papua (APEC 2013). To address the cost differences and the goal to increase electrification rates, Indonesia designed its FIT with different rates based on the location of the project. In regions where it is least expensive to generate electricity currently (e.g., Java and Bali), the FIT is approximately $50 \%$ lower than the FIT in Papua, where electricity costs are higher. Indonesia provides a strong example of a country harnessing the flexibility of FIT design to support varying circumstances and development goals at the subnational level.

energy generation can be bid into day-ahead and intra-day markets, which can allow for optimized generation. In high penetration contexts, linking FITs to wholesale market prices can also increase efficiency of policy outcomes and decrease costs (Miller et al. 2013; Miller and Cox 2014). 


\section{Conclusion}

FITs are an important policy tool supporting global deployment of renewable energy technologies. Innovative policies building on the FIT approach, such as reverse auctions, offer significant potential for accelerating renewable energy expansion (Couture et al. 2015). The key FIT design elements described in this brief provide a starting point for considering a country-specific and tailored policy approach to support deployment of renewable energy in various country contexts. 


\section{References}

APEC (Asia-Pacific Economic Cooperation). 2013. APEC Energy Overview 2013. Asian Pacific Energy Research Centre.

http://aperc.ieej.or.jp/file/2014/3/18/APEC_Energy_Overview_2013.pdf.

Couture, Toby D., David Jacobs, Wilson Rickerson, and Victoria Healey. 2015. The Next

Generation of Renewable Electricity Policy: How Rapid Change Is Breaking Down

Conventional Policy Categories. Golden, CO: National Renewable Energy Laboratory.

http://www.nrel.gov/docs/fy15osti/63149.pdf.

Couture, Toby D., Karlynn Cory, Claire Kreycik, and Emily Williams. 2010. A Policymaker's Guide to Feed-in Tariff Policy Design. Golden, CO: National Renewable Energy Laboratory. http://www.nrel.gov/docs/fy10osti/44849.pdf.

Eberhard, Anton, Joel Kolker, and James Leigland. 2014. South Africa's Renewable Energy IPP Procurement Program: Success Factors and Lessons. Public Private Infrastructure Advisory Facility. http://www.ppiaf.org/sites/ppiaf.org/files/publication/South-Africa-REIPP-

Report_final_web.pdf.

EIA (U.S. Energy Information Administration). 2015. Annual Energy Outlook. Washington, D.C.: EIA. http://www.eia.gov/forecasts/aeo/electricity generation.cfm.

Miller, M., L. Bird, J. Cochran, M. Milligan, M. Bazilian, E. Denny, J. Dillon, J. Bialek, M. O'Malley, and K. Neuhoff. 2013. RES-E-NEXT: Next Generation of RES-E Policy Instruments. Utrecht, Netherlands: International Energy Agency Renewable Energy Technology Deployment. http://iea-retd.org/wp-content/uploads/2013/07/RES-E-NEXT_IEA-RETD_2013.pdf.

Miller, Mackay, and Sadie Cox. 2014. Overview of Variable Renewable Energy Regulatory Issues: A Clean Energy Regulators Initiative Report. Golden, CO: National Renewable Energy Laboratory. http://www.nrel.gov/docs/fy14osti/61350.pdf.

NREL (National Renewable Energy Laboratory). 2014. "Feed-in Tariffs." Last modified September 8. http://www.nrel.gov/tech_deployment/state_local_governments/basics_tariffs.html.

REN 21 (Renewable Energy Policy Network for the 21st Century). 2015. Renewables 2014: Global Status Report. Paris: REN 21.

http://www.ren21.net/status-of-renewables/global-status-report/.

Rickerson, Wilson H., Janet L. Sawin, and Robert C. Grace. 2007. "If the Shoe FITs: Using Feed-in Tariffs to Meet U.S. Renewable Electricity Targets," The Electricity Journal 20 (2007): 73-86. doi:10.1016/j.tej.2007.03.007.

Stadelmann, Martin, Gianleo Frisari, and Anja Rosenberg. 2014. The Role of Public Finance in CSP: Lessons Learned. San Francisco: Climate Policy Initiative. http://climatepolicyinitiative.org/wp-content/uploads/2014/06/The-Role-of-Public-Finance-inCSP-Lessons-Learned.pdf. 


\section{Appendix. Additional Support and Resources}

Targeted technical assistance regarding the design and implementation of renewable energy policies is provided by:

- Clean Energy Solutions Center Ask an Expert-The Solutions Center Ask an Expert service is available at no cost to government agency representatives from any country and the technical institutes assisting them. If your request qualifies for assistance, you will be matched with the Solutions Center expert who is most qualified to help you, for up to 40 hours of assistance. For more information, see cleanenergysolutions.org/expert.

- Climate Technology Center \& Network (CTCN) - Climate Technology Center \& Network (CTCN) - The CTCN provides technical assistance in response to requests submitted by developing countries via their National Designated Entities (NDEs). Upon receipt of such requests, the CTC quickly mobilizes its global Network of climate technology experts to design and deliver a customized solution tailored to local needs. The CTCN does not provide funding directly to countries, but instead supports the provision of technical assistance provided by experts on specific climate technology sectors. For more information, see ctcn.org/technical-assistance.

Additional resources - including good practice resources and publications, policy examples and databases, webinars and training resources, and a glossary - are available at cleanenergysolutions.org/policy-briefs/fit/resources. 